\title{
Plastic Packages for Personal Care Products - Evaluation of Light Barrier Properties
}

\author{
Leda Coltro, Joyce Borghetti \\ CETEA- ITAL
}

Abstract: The use of transparent packages has great marketing appeal since they allow consumers to actually see the product they wish to buy. However, the light that passes through the packaging material may catalyze oxidation reactions in photosensitive products and reduce their shelf life. The use of UV absorbers in packages for personal care products is an increasing tendency in the market due to growing consumer preference for more natural, non-additive products. UV absorbers prevent photo-degradation of the product as a result of the UV light barrier properties of the packaging, which protect the product against UV rays in the wavelength range of 200-380 $\mathrm{nm}$. Although a number of studies indicate the need for the use of UV absorbers, they do not mention any technical reference data that could be used as quality parameters for packaging systems. Therefore, the objective of this study was to evaluate the effectiveness of UV absorbers as light barriers in plastic packages of personal care products in order to generate technical data required to establish specifications for these packaging systems.

Keywords: Plastic packages, PET, HDPE, PP, PVC, personal care, UV absorber, light barrier.

\section{Introduction}

Radiation energy from light or artificial sources - either ultraviolet or visible light - significantly affects the stability of photosensitive products, since it catalyzes and accelerates photochemical degradation reactions that have a deterioration effect on such products. In addition, polymers are known to undergo oxidative degradation when exposed to light, thereby causing discoloration and weakening of the polymer. This, in turn, compromises the physical and mechanical properties of the packages, which may even lead to degradation of the products in contact with the packaging materials. In other words, ultraviolet light has photo-oxidative effects that may cause, among other damages, breaking of polymer chains and photo-oxidation ${ }^{[1]}$.

Although ultraviolet radiation is a rather narrow range of the electromagnetic spectrum (200 to $380 \mathrm{~nm}$ ), UV light has more energy per photon than visible light (380 to $780 \mathrm{~nm}$ ), since the amount of energy light rays carry is directly proportional to their frequency and inversely proportional to their wavelength: the shorter the wavelength, the higher the radiation energy ${ }^{[2]}$. Consequently, UV rays carry more energy than visible light and cause higher oxidation rates. This explains why UV light is responsible for most photochemical oxidation reactions. For that reason, organic compounds are used as light stabilizers in a wide variety of plastic resins to prevent photo-degradation caused by sunlight and artificial UV light.

Light stabilizers are classified as anti-aging additives and are used to protect packages and products against photo-oxidative degradation reactions caused by the UV-light to which they are exposed. Light stabilization is performed through different mechanisms depending on the nature of the additive. There are three classes of light stabilizers: 1) UV absorbers; 2) free radical scavengers; 3) excited-state quenchers. Each class of light stabilizer acts in a different phase of the reaction sequence of photochemical degradation. UV absorbers account for about $50 \%$ of the global demand (in metric tons) for light stabilizers. Most ultraviolet light absorbers are derived from benzophenone or benzotriazole and act in the initial phase of the degradation process as they absorb UV radiation energy and prevent the formation of free radicals. Polyolefins alone (PP, HDPE, LDPE e LLDPE) are responsible for more than $70 \%$ of the light stabilizers marketed in the world ${ }^{[3]}$.

Also some pigments have been incorporated into plastic materials to provide protection against photo-degradation processes. Maatoug ${ }^{[4]}$ studied photo-degradation processes of high density polyethylene films (HDPE) containing phtalocyanine - or $\mathrm{TiO}_{2}$-based pigments as well as non-pigmented films containing different concentrations of light stabilizers. According to the authors, films containing phtalocyanine-based pigments exhibited degradation characteristics (abrupt reduction of elongation at break after short exposure to UV, non-formation of gel and high concentrations of oxygen-containing functional groups on the surface) similar to those exhibited by films containing low levels of light stabilizer.

The need to provide protection against UV light is not limited to polymers alone, but also applies to the products packaged in transparent plastic packages since most industrial products are typically put on shelves at retail markets

Autor para correspondência: Leda Coltro, CETEA - ITAL, Av. Brasil 2880, Caixa Postal 139, CEP: 13070-178, Campinas, SP, Brasil. E-mail: ledacolt@ital.sp.gov.br 
where they are likely to be exposed to light and, consequently, subjected to photo-oxidation.

A good example of a photo-sensitive product is edible oil. Light-induced oxidation of its lipid content may have significant consequences as it causes browning and off-flavors. Therefore, when edible oil is filled into transparent packages, light-induced lipid oxidation becomes the primary cause of oxidative degradation which considerably shortens the shelf life of the product. Adequate protection of the food product can be achieved by incorporating UV absorbers - colorless substances that absorb the UV energy emitted by any light source and deactivate excited chromophores - into the packaging materials ${ }^{[5-8]}$.

However, not only foods are sensitive to light. Cosmetics are also subject to photo-degradation. $\mathrm{Wu}^{[9]}$ found that betadi-carbonyl-based compounds may effectively stabilize photo-degradation of polyisopropylene in alcohol solutions as a result of a photo-enolization reaction catalyzed by UV light. For that reason, photo-stabilization of formulas containing alcohol has potential applications in the protection of cosmetics against photo-aging reactions.

Photo-catalyzed degradation has also been observed in mixtures of surfactants and commercial soap and detergent formulas ${ }^{[10]}$. Consequently, photo-oxidation reactions reduce the shelf life of the product by causing undesirable changes such as loss of color and/or neutralization-inactivation of the active component of the solution.

Hence, light has a strong catalyzing effect on the oxidation of both food and non-food products. Often, the amount of residual $\mathrm{O}_{2}$ in the headspace of the package is sufficient to catalyze oxidation reactions that affect certain components of the product. In order to provide efficient protection against the deterioration caused by exposure to light, packages should have low oxygen permeability and be manufactured from packaging materials that contain additives or pigments with good light barrier properties since light plays a major role as catalyzer of photo-degradation reactions.

There is a wide variety of UV absorbers available on the market. Most manufacturers offer a range of specification options, including products with customized UV barrier properties, such as for example materials with UV light barrier up to $370 \mathrm{~nm}$ or with transmittance equal to or less than $5 \%$ at $390 \mathrm{~nm}$. As personal care products are becoming more and more sophisticated every day with the incorporation of color agents, fragrances and vitamins, effective protection against UV rays will become increasingly more important ${ }^{[11]}$.

Isolated case studies conducted at CETEA/ITAL over the past few years indicate that the shelf life of certain product types is negatively impacted by the catalyzing effect of light on degradation processes that may affect the product and/or the package. This has lead to the use of light stabilizers in transparent plastic packages in an attempt to combine consumer appeal (transparency of the package) and product protection (UV light barrier properties provided by the light stabilizer). Although the studies available in this field indica- te the need for and use of light stabilizers, they do mention any technical reference data (for example:. concentration of the additive vs. UV light barrier property - effectiveness of the additive) that might be used as quality parameter for packaging systems.

For that reason, the objective of this study was to evaluate the use and efficacy of UV absorbers as light barrier promoters into plastic packages for personal care products, in order to elaborate and make available technical specifications for light-sensitive products packages.

\section{Experimental}

\section{Material}

A total of 29 transparent plastic packages for several light-sensitive personal care products available on the Brazilian market were purchased from local retail outlets in the greater Campinas area during the year 2004. These packages were submitted to a series of tests to evaluate their light barrier properties. The packages investigated in this study were selected based on the type of packaged product, with an emphasis on transparent packages and considering the representativeness of the packaged product on the Brazilian market.

The different classes of personal care products sensitive to light whose packages were evaluated are shown in Table 1.

The reagents acetonitrile, HPLC grade (Merck, Germany), methanol, HPLC grade (Merck, Germany), dichloromethane, p.a. grade (Merck, Germany) and ultrapure water (Milli-Q) were not purified prior to use.

UV absorbers Tinuvin $\mathrm{P}^{\mathrm{TM}}$, Tinuvin $326^{\mathrm{TM}}$, Tinuvin $327^{\mathrm{TM}}$ e Tinuvin $234^{\mathrm{TM}}$, supplied by Ciba Specialty Chemicals Inc. (Basel, Switzerland), were used as standard. The additives were used in the state they were received (i.e. without any purification).

\section{Methods}

The plastic packages were conditioned at a temperature of $23 \pm 2{ }^{\circ} \mathrm{C}$ for at least 40 hours prior to analysis. All tests were carried out at the same temperature used to condition the samples. The samples were characterized as follows: 5 (five) bottles of the sample containing a UV absorber in its formula and 1 (one) bottle of the sample in which the presence of such additive had not been detected.

\section{Light transmission}

The percentage of light transmission was determined based on the method described by Alves ${ }^{[12]}$. The percentage of regular light transmission (i.e. the transmittance value obtained by measuring only the light transmitted in the same direction of the incident beam, that is, with a deviation smaller than 1 degree from the incident angle) of the samples was determined using a double beam UV-Visible spectrophotometer (Perkin Elmer, model Lambda 3B) scanning the ultraviolet 
Table 1. Personal care products evaluated in this study.

\begin{tabular}{|c|c|c|c|c|c|}
\hline Material & Product & Sample & Total volume $(\mathrm{mL})$ & Mass (g) & Minimum body thickness $(\mu \mathrm{m})$ \\
\hline HDPE & Shampoo & 1 & 352.6 & 25.7 & 0.59 \\
\hline HDPE & Shampoo & 2 & 325.2 & 24.9 & 0.59 \\
\hline HDPE & Shampoo & 4 & 375.5 & 27.7 & 0.68 \\
\hline HDPE & Shampoo & 5 & 430.1 & 30.4 & 0.59 \\
\hline HDPE & Hair conditioner & 3 & 324.5 & 20.2 & 0.51 \\
\hline PET & Shampoo & 6 & 313.4 & 32.5 & 0.44 \\
\hline PET & Shampoo & 7 & 440.5 & 28.0 & 0.38 \\
\hline PET & Shampoo & 8 & 338.6 & 22.5 & 0.40 \\
\hline PET & Shampoo & 9 & 376.0 & 30.5 & 0.43 \\
\hline PET & Shampoo & 10 & 312.1 & 34.9 & 0.51 \\
\hline PVC & Hair conditioner & 11 & 305.8 & 31.9 & 0.57 \\
\hline PVC & Hair conditioner & 12 & 362.7 & 34.5 & 0.54 \\
\hline PVC & Shampoo & 13 & 225.5 & 30.0 & 0.49 \\
\hline PP & Hair conditioner & 14 & 328.6 & 25.9 & 0.61 \\
\hline PP & Shampoo & 15 & 379.5 & 28.4 & 0.66 \\
\hline PP & Shampoo & 16 & 376.5 & 27.1 & 0.66 \\
\hline PP & Shampoo & 17 & 257.8 & 21.5 & 0.75 \\
\hline HDPE & Body deodorant & 18 & 430.2 & 35.6 & 0.82 \\
\hline PET & Body deodorant & 19 & 125.4 & 20.8 & 0.77 \\
\hline HDPE & Shower gel & 20 & 219.5 & 21.2 & 0.46 \\
\hline PP & Shower gel & 21 & 267.0 & 21.5 & 0.62 \\
\hline PET & Shower gel & 22 & 132.7 & 11.8 & 0.26 \\
\hline HDPE & Shower gel & 23 & 182.1 & 17.6 & 0.45 \\
\hline $\mathrm{PP}$ & Facial cleanser gel & 24 & 162.0 & 16.0 & 0.70 \\
\hline PET & Antiseptic mouth cleanser & 25 & 319.1 & 28.1 & 0.33 \\
\hline PET & Antiseptic mouth cleanser & 26 & 274.2 & 29.6 & 0.38 \\
\hline PET & Antiseptic mouth cleanser & 27 & 275.0 & 26.6 & 0.47 \\
\hline PET & Antiseptic mouth cleanser & 28 & 270.8 & 26.6 & 0.49 \\
\hline PET & Antiseptic mouth cleanser & 29 & 271.3 & 27.1 & 0.42 \\
\hline
\end{tabular}

(200 to $380 \mathrm{~nm}$ ) and the visible ( $380 \mathrm{a} 800 \mathrm{~nm}$ ) light ranges. The spectra were registered at a scanning rate of $60 \mathrm{~nm} / \mathrm{min}$.

Sample specimens were cut out from three different sections of the plastic bottles (top, body, bottom) and had the following approximate dimensions: $10 \mathrm{~mm}$ wide $\times 40 \mathrm{~mm}$ long. The test specimens thus obtained were free from dirt, printing and were representative of the sample units.

\section{UV absorber quantification}

The method used to extract the UV absorber from the plastic sample specimens was based on the method described by Machado ${ }^{[13]}$. Small sample specimens were cut out of 3 different sections of the packages (top, body and bottom) and placed in direct contact with dichloromethane for 12 hours. Next, extraction was performed by immersing the sample specimens in an ultrasonic bath for 1 hour. After extraction, the sonicated solution was filtered through Whatman $\mathrm{n}^{\circ} 1$ filter paper and the volume completed to $50 \mathrm{~mL}$ with dichloromethane. Next, the completed, UV absorbercontaining solution was filtered again through a $0.45 \mu \mathrm{m}$ pore size filter and subsequently injected into a high performance liquid chromatograph (HP Model 1100, equipped with a UV-Visible photo-diode-array detector) under the following conditions: LiChrospher 100 RP-18 reverse-phase column, $250 \times 4 \mathrm{~mm}$; column temperature: $40{ }^{\circ} \mathrm{C}$; mobile phase: $100 \%$ acetonitrile; flow rate: $1.5 \mathrm{~mL} / \mathrm{min}$; detector: $200 \mathrm{~nm}$; and sample size: $10 \mu \mathrm{L}$.

The amount of UV absorber in the PET samples was determined from 2 to 5 replicates. Only samples of packages that showed a positive result for UV absorbers in the light transmission test were submitted to this analysis. In the case of the other plastic materials (HDPE, PP, PVC, etc.) other extraction solvents were used: cyclohexane, dichloromethane, trichloromethane, etc.

\section{Results and Discussion}

\section{Evaluation of light barrier}

The light transmission spectra of the plastic packages investigated in this study were grouped together according to 
product class and/or material type (hair products, body deodorant, shower gel, facial cleansers and antiseptic mouth cleanser products).

HDPE packages (Figure 1) have ultraviolet (UV) and visible light barrier properties since they are primarily made of a material that is semi-crystalline in nature and, hence, translucent. It should be noted that this study evaluated only the regular light transmission rate (without deviation from the incident angle) and that a portion of the total light that passes through these materials consists of scattered light, or haze. The differences in light barrier properties between the samples evaluated do not correlate with wall thickness, since all the samples exhibited minimum wall thickness of $0.60 \mathrm{~mm}$ at the midsection of the bottle. Sample 3 exhibited the highest light barrier of all the samples investigated as a result of the red pigment this material contains. This bottle provides good protection against light, since it allows for the passage of only $10 \%$ of the longer wavelengths. However, the material of the bottle had no resistance to the effects of incident light and showed signs of discoloration. The clearest section of the bottle (greatest discoloration) was found to have lower light barrier properties (greater transmittance) than the darker section of the package (less affected by incident light).

This means that, although the product might be adequately protected against the detrimental effects of light by the light barrier of the package, the same did not apply to the packaging material. This result clearly illustrates the need, in this case, to incorporate a UV absorber into the packaging material in order to protect the package and not the product.

In the case of Sample 1, the light barrier of the bottle was improved by using a printed sleeve label (applied over the bottle and shrunk to the entire body contour of the bottle). Here, the light barrier (average light transmission $\leq 5 \%$ ) was provided by the printing inks.

The light barrier properties of the Samples 6, 7 and 9 of the PET packages for hair products (Figure 2) indicate that the packaging materials of these samples most probably contain a UV light absorber in their formula. What indicates the presence of UV absorbers in these samples is the significant reduction in percentage transmittance in the wavelength range 300 to $400 \mathrm{~nm}$, a feature that does not occur in PET reference sample (without UV absorber).

These diverse light barrier of the bottles may be the result of: 1) the use of different additives, 2) the use of the same additive, but at different concentrations, or 3) the differences in wall thickness between the samples (Table 1). On the other hand, the Sample 8, also made of PET showed high light barrier throughout the $\mathrm{UV}$ and visible light range $(\mathrm{T}=0 \%)$ due to the green pigment added to the material.

The PVC package labeled as Sample 11 showed high transmittance in the visible range $(\mathrm{T}=80 \%)$, but also - unlike Samples 12 and 13 (Figure 3) - a sharp drop in light transmission in the UV range $(<380 \mathrm{~nm})$. Therefore, Sample 11 most probably contains a UV absorber in the formula of the packaging material.

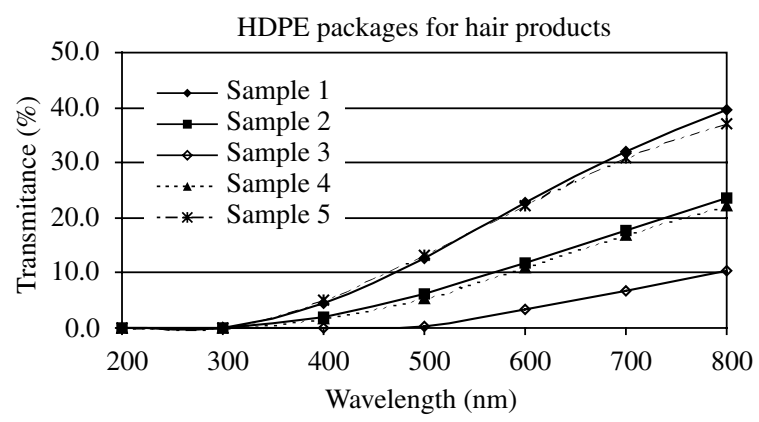

Figure 1. Regular light transmission spectra of HDPE bottles for hair products.

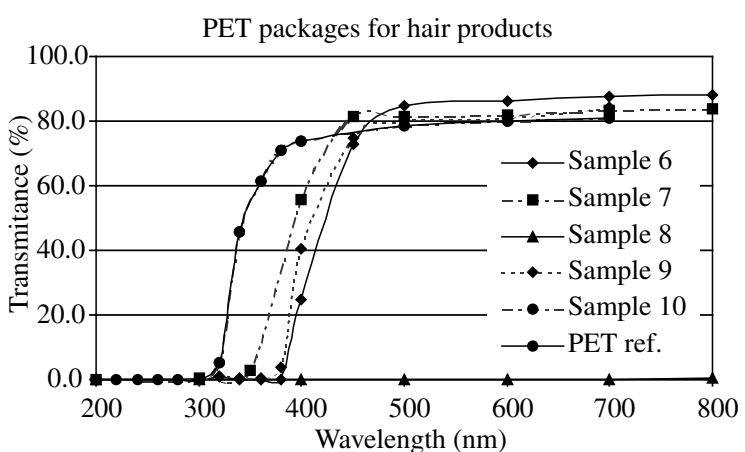

Figure 2. Regular light transmission spectra of PET bottles for hair products.

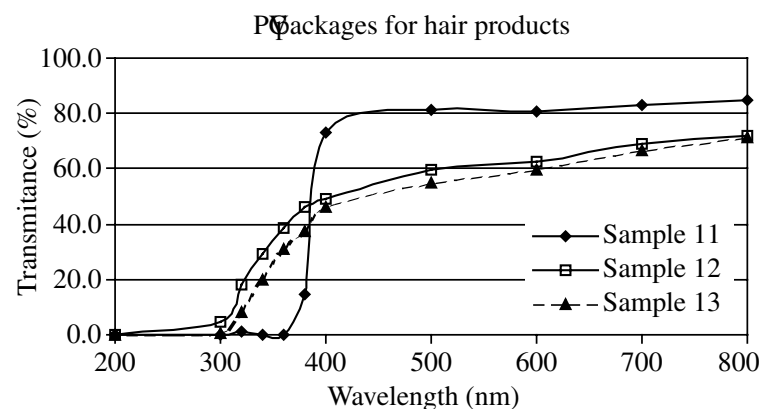

Figure 3. Regular light transmission spectra of PVC bottles for hair products.

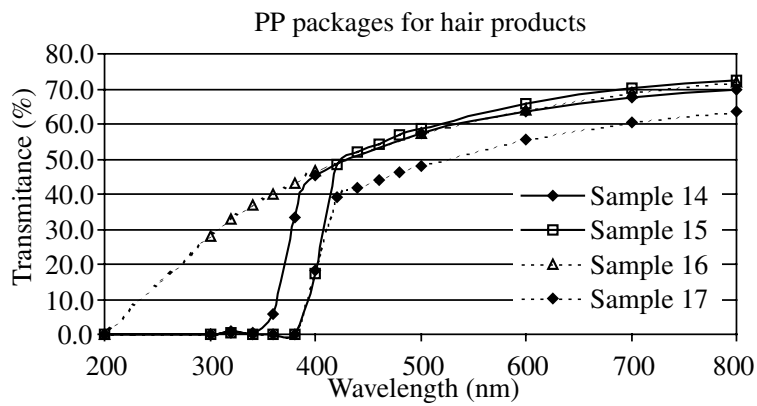

Figure 4. Regular light transmission spectra of PP bottles for hair products.

Likewise, the light transmission spectrum profile of the PP bottles of Samples 14, 15 and 17 are indicative of the possible presence of a UV absorber in the packaging material. On the other hand, Sample 16 did not contain any UV absorber (Figure 4). It is interesting to note that in spite of the PP and HDPE bottles being translucent, the PP bottles exhibited hi- 
gher transmission compared to the HDPE packages (Figure 1) and, hence, allow for a better view of the packed product.

The light transmission spectrum of the plastic packages for body deodorant indicates the presence of a UV absorber in the PET bottle of Sample 19 since it was found to have high light barrier in the wavelength range below $380 \mathrm{~nm}$ - a characteristic typical of PET packages containing a UV absorber. On the other hand, the lower light transmission of the Sample 18 is a consequence of the plastic material of the bottle (HDPE) that is translucent while the PET bottle (Sample 19) is transparent and, then, shows high light transmission in the visible region.

The light transmission spectra of Samples 20 and 23 (plastic packages for shower gel) are typical for HDPE packaging materials. The spectrum of Sample 21 - PP bottle - showed light barrier in the UV range, probably due to the presence of a UV absorber, and moderate light barrier in the visible range, since the packaging material contained blue pigment. The PET package of Sample 22 probably contains a UV absorber, as can be deducted from the reduction in light transmission in the wavelength range below $380 \mathrm{~nm}$.

The PP package for facial cleanser (Figure 5) was also blue-pigmented, but in a darker color range than Sample 21 for shower gel, which explains the higher light barrier in the 600 to $700 \mathrm{~nm}$ range. This package probably also contains a UV absorber, as evidenced by its light barrier capacity in the wavelength range below $380 \mathrm{~nm}$.

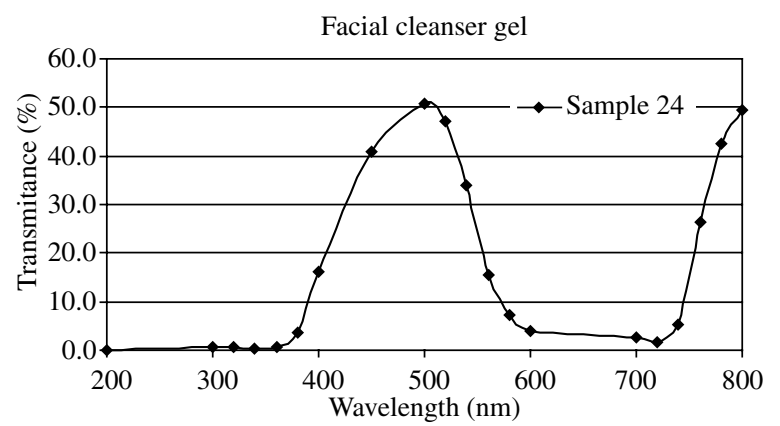

Figure 5. Regular light transmission spectrum of PP bottle for facial cleanser gel.
The PET packages of Samples 28 and 29 (antiseptic mouth cleansers) showed light barrier in the UV range which is indicative of the presence of a UV absorber in the packaging material. Sample 25 showed higher transmittance than Sample 26 probably due to its smaller wall thickness.

The results showed that the personal care products packaged in plastic packages containing a UV absorber were better protected against photo-degradation, due to the light barrier of the packaging material in the UV range. Only pigmented packaging materials would provide higher light barrier (in the UV and visible range). The darker the color range of the pigment, the higher the light barrier.

The plastic packages that did not exhibit any barrier to UV light are probably used to hold products that are either not susceptible to photo-oxidation or that were previously stabilized with antioxidant compounds. Some products showed signs of yellowing and/or discoloration after exposure to light, but this sensitivity greatly depends on the product formula.

The shelf life of the personal care products whose packages were evaluated ranged from 3 to 4 years (according to the producers information). No correlation of any kind could be established between the shelf life and the use of a UV absorber in the packaging material.

\section{UV absorber quantification}

The packages for personal care products having a light transmission spectrum typical of materials containing a UV absorber additive were submitted to solvent extraction. After extraction, aliquots of the extraction solution were injected into a HPLC system for identification of the additive by comparing retention time and UV spectrum with UV absorber standards. Table 2 shows the amounts of UV absorber determined in the packages investigated. All the samples were found to contain a UV absorber known by the commercial name Tinuvin $326^{\mathrm{TM}}$.

Sample 6 of the packages for hair products and Sample 19 of those for body deodorant contained in their material formula - in addition to Tinuvin $326^{\mathrm{TM}}$ - a second UV absorber, commercially known as Tinuvin $\mathrm{P}^{\mathrm{TM}}$. These two additives together provide the packaging material with excellent UV

Table 2. UV absorber quantification for the plastic packages for personal care products evaluated (mg/kg).*

\begin{tabular}{llccccc}
\hline \multicolumn{1}{c}{ Material } & \multicolumn{1}{c}{ Product } & Sample & UV absorber** & Average & Variation range & RSD (\%) \\
\hline PET & Shampoo & 6 & 1 & $1644^{\mathrm{a}}$ & $1613-1674$ & 2.6 \\
& & & 2 & $1005^{\mathrm{a}}$ & $982-1029$ & 3.3 \\
PET & Shampoo & 7 & 1 & $509^{\mathrm{c}}$ & $480-532$ & 4.2 \\
PET & Shampoo & 9 & 1 & $609^{\mathrm{b}}$ & $593-642$ & 3.8 \\
PP & Shampoo & 15 & 1 & $2140^{\mathrm{b}}$ & $2091-2231$ & 2.0 \\
PP & Shampoo & 17 & 1 & $1358^{\mathrm{b}}$ & $1331-1397$ & 1.6 \\
PET & Body deodorant & 19 & 1 & $590^{\mathrm{a}}$ & $589-590$ & 0.1 \\
& & & 2 & $1100^{\mathrm{a}}$ & $1076-1125$ & 3.1 \\
PP & Shower gel & 21 & 1 & $742^{\mathrm{a}}$ & $731-754$ & 2.1 \\
PET & Antiseptic mouth cleanser & 29 & 1 & $281^{\mathrm{c}}$ & $263-290$ & 4.9 \\
\hline
\end{tabular}

*Results obtained from (a) 2; (b) 4 or (c) 5 replicates; **UV absorber 1: Tinuvin $326^{\mathrm{TM}}$ and UV absorber 2: Tinuvin P ${ }^{\mathrm{TM}}$; RSD: relative standard deviation. 
barrier properties (Figure 2) and, consequently, more effective protection to the packed product. The combined use of two UV absorbers in the same packaging material probably reflects the fact that these products contain active compounds of higher light sensitivity in their formulas than the other personal care products investigated in this study.

Since the Samples 7 and 9 have the same UV absorber in their composition and its concentration are quite similar, probably the higher UV barrier of the Sample 9 (Figure 2) is related to its higher thickness (approx. 15\%).

Since the light transmission spectrum of HDPE has low transmittance and part of the light in the visible spectrum, some HDPE samples were suspected to contain UV absorber in their composition. These samples were submitted to extraction and the extraction solutions injected in the HPLC system. Liquid extractions were performed using a series of different solvents: cyclohexane, dichloromethane and trichloromethane. None of these samples was found to contain any UV absorber - only antioxidants (which are regarded as standard additives for this material).

There are no specific rules and regulations relating to plastic packages for personal care products. However, the industry uses as reference for their product specifications the same legal requirements as those applicable to packaging materials intended to be placed in contact with foods. All additives identified in this study, as well as the concentrations in which they are used, are approved for contact with food products ${ }^{[14]}$.

\section{Conclusions}

The results of this study show that:

- Approx. 35\% of the evaluated plastic packages for personal care products were found to contain one or more UV absorbers;

- All the UV absorber containing samples exhibited the presence of the same UV absorber additive (Tinuvin $\left.326^{\mathrm{TM}}\right)$;

- Two of the evaluated packages also contained a second UV absorber in their composition (Tinuvin $\mathrm{P}^{\mathrm{TM}}$ ) probably because of the higher light sensitivity of the packed products; and

- The UV absorbers detected in the plastic packages for personal care products are approved for packaging intended for use in contact with foodstuff.

\section{Acknowledgements}

The authors wish to thank FAPESP for the financial support supplied to this research and $\mathrm{CNPq}$ for the scholarship granted to Joyce Borghetti.

\section{References}

1. Espinoza-Atencia, E.J., Faria, J.A.F. \& Anjos, C.A.R. - "Efeito de Absorvedor de Ultravioleta em Embalagens de Polietileno Tereftalato para Óleos Comestíveis", in: Anais do 8th IPRI World Conference on Packaging, 2, p.861, São Paulo - SP (1993).

2. Silverstein, R.M., Bassler, G.C. \& Norril, T. - "Identificação Espectrométrica de Compostos Orgânicos.”, Alencastro, R.B. \& Roberto de Faria, R.B. (trad.). $3^{\mathrm{a}}$ ed. Rio de Janeiro, Guanabara, p. 203 (1987).

3. Zweifel, H. (ed.) - "Plastics Additives.Handbook", 5ª ed., Hanser Publishers, Munich (2001).

4. Maatoug, M.A., Anna, P., Bertalan, G., Ravaditis, I., Marosi, G., Csontos, I., Marton, A. \& Toth, A. - Macromolecular Mat. Eng., 282, p.30 (2000).

5. Azeredo, H.M.C., Conceiçaõ, M. P. J. \& Faria, J. A. F. - Óleos \& Grãos, 55, p.24 (2000).

6. Coltro, L., Padula, M.,Saron, E. S., Borguetti, J. \& Buratin, A E. P. - Pack. Techn. Sci., 16, p.15 (2003).

7. Coltro, L \& Buratin, A.E.P. - Polímeros: Ciência e Tecnologia, 14, p.205 (2004).

8. Pascall, M.A., Harte, B.R., Giacin, J.R. \& Gray, J.I. - J. Food Sci., 60(5), p. 1116 (1995).

9. Wu, S.K., Chang, Y.F., Mou, Y. \& Babek, J.F. - Polymer Bulletin, 26(4), p. 423 (1991).

10. Rao, N.N. \& Dube, S. - J. Molecular catalysis A - Chem. 104(3), p. L197 (1996).

11. Trends and New Materials in Additives for PET Bottles. Retrieved on 02/02/2006 at: http://www.specialchem4polymers.com/resources/articles

12. Alves, R.M.V., Oliveira, L.M., Coltro, L., Garcia, E.E.C., Sarantópoulos, C.I.G.L. \& Padula, M. - "Ensaios para Avaliação de Embalagens Plásticas Rígidas", CETEA/ ITAL, Campinas (1998).

13. Machado, M.C.M.S.T. - "Absorvedores de Radiação Ultravioleta em Embalagens Plásticas em Óleos Vegetais: Metodologia Analítica e Estudo de Migração". Tese de Doutorado, Universidade Estadual de Campinas, Brasil (1997).

14. Agência Nacional de Vigilância Sanitária - ANVISA - "Disposições gerais para embalagens e equipamentos plásticos em contato com alimentos e seus anexos". Resolução n. 105, de 19 de maio de 1999. Diário Oficial (da República Federal do Brasil), Brasília, p.21-34, 20 de maio de 1999. Sec.I.

Enviado: 28/08/06

Reenviado: 06/11/06

Aprovado: 07/11/06 